\title{
Bronchial hyperreactivity in potroom workers and prognosis after stopping exposure
}

\author{
M Šarić, J Marelja
}

\begin{abstract}
A group of 30 potroom workers who developed an asthma-like syndrome during their work in the electrolytic extraction of aluminium (AluSwiss process with prebacked anodes) was followed up after stopping exposure. Subjective respiratory complaints were registered and a non-specific bronchial reactivity test using methacholine was performed once or twice during the follow up period (1984-9). After transfer to other work most workers either had an improvement in respiratory symptoms $(60 \%)$ or even normalisation $(27 \%)$; only $13 \%$ did not show changes. Bronchial hyperreactivity remained unchanged in $67 \%$ of workers, was less pronounced in $13 \%$, normalised in $13 \%$, and deteriorated in $7 \%$. Smoking habits, atopy, and duration of exposure did not seem to have influenced the results obtained. No significant correlation was found between duration of exposure and the speed of onset of respiratory symptoms and the later prognosis of the syndrome. Based on the information collected during the period of observation it appears that reactive airway dysfunction syndrome, once induced, has a tendency to persist. An improvement in subjective complaints may be expected, however, after stopping exposure.
\end{abstract}

The development of an asthma-like respiratory syndrome was seen in potroom workers. ${ }^{1}$ According to previous studies the impairment could be explained by induced bronchial hyperreactivity based on functional imbalance of the autonomic nervous system; increased vagal activity resulting in increased sensitivity to potroom fumes and dusts. ${ }^{2}$ An investigation aimed at evaluating a possible allergic reaction produced no evidence for such a mechanism. ${ }^{3 .}$ In the

Institute for Medical Research and Occupational Health, University of Zagreb, 158 Mose Pijade, PO Box 291, Zagreb YU-41001, Yugoslavia M Sarić

Health Unit, TLM, Sibenik, Yugoslavia J Marelja meantime, the results of other studies have been in accordance with these findings. ${ }^{45}$

The purpose of the present study was to evaluate the persistence of reactive airway dysfunction syndrome after stopping exposure.

\section{Sample and methods}

A group of 30 male potroom workers who developed an asthma-like syndrome during their work in the electrolytic extraction of aluminium (Alu-Swiss process with prebacked anodes) was followed up after stopping exposure. Subjective respiratory complaints were registered and a non-specific bronchial reactivity test using methacholine (acetyl-betamethacholine chloride) was performed once or twice during the follow up period (1984-9). The findings were compared with those during a previous period of exposure.

Bronchial reactivity was tested using the method of continuous nebulisation and intermittent aerosol inhalation with a fixed number of non-dosimeter regulated breaths at the same volume and different methacholine concentrations. Methacholine was diluted in physiological solution to the concentrations: $0.08,0.15,0.31,0.62,1.25,2.50,5 \cdot 00,10 \cdot 0$, and $25.0 \mathrm{mg} / \mathrm{ml}$. The first concentration was considered as zero and the last one as eight. The cumulative inspired dose that caused a drop in $\mathrm{FEV}_{1.0}$ of more than $20 \%$, compared with the value measured after the inhalation of physiological solution, was taken as $\mathrm{FEV}_{1.0}\left(\mathrm{PD}_{20}\right)$. A 46.5 cumulative dose unit was considered to be the limit value that served to distinguish a hyperreactive person from a normoreactive one. An improvement in the follow up was taken as the result of testing in which reactivity was obtained only at concentration of methacholine next to the value after the one which caused a positive reaction at previous testing.

\section{Results}

Table 1 shows workers' ages, durations of employment and exposure, smoking habits, and signs of atopy.

Table 2 presents the results of the follow up of potroom workers after stopping exposure compared with those in the period with exposure. 
Table 1 Workers by age, duration of employment and exposure, smoking habit, and signs of atopy

\begin{tabular}{lc}
\hline Mean age $(y)^{\star}$ & $40 \cdot 6(25-59)$ \\
Mean duration of employment $(y)^{\star}$ & $17 \cdot 3(5-30)$ \\
Mean duration of exposure in potrooms $(y)^{\star}$ & $8 \cdot 5(1-21)$ \\
Smoking habit: & 10 \\
No of present smokers & 3 \\
No of past smokers & 17 \\
No of non-smokers & 0 \\
Atopy in family & 13 \\
Intradermal skin testing with common allergens: & 16 \\
$\quad$ Positive & 1 \\
Negative & \\
Without data & 12 \\
IgE concentration: & 17 \\
Increased value (above $125 \mathrm{kU} / \mathrm{L})$ & 1 \\
Normal values & \\
Without data & \\
\hline
\end{tabular}

^Range in parentheses.

Table 2 Respiratory findings in workers after stopping exposure compared with findings during period with exposure

\begin{tabular}{lc}
\hline \multicolumn{2}{c}{ No of workers } \\
\hline Subjective respiratory complaints: \\
Without changes & 3 (with atopy 1 ; without atopy 2 ) \\
Improvement & 18 (with atopy 8; without atopy 10) \\
Normalisation & 8 (with atopy 3; without atopy 5) \\
Bronchial hyperreactivity: & \\
Without changes & 19 (with atopy 8; without atopy 11) \\
Improvement (slight) & 4 (with atopy 3; without atopy 1) \\
Normalisation & 4 (with atopy 1; without atopy 3) \\
Deterioration & 2 (with atopy 0; without atopy 2) \\
$\begin{array}{l}\text { Mean follow up period (y) } \\
\text { (range) }\end{array}$ & $3 \cdot 7$ (2-11) \\
\hline
\end{tabular}

In one subject without data concerning intradermal skin testing and IgE value subjective and objective findings during the follow up period were unchanged.

Table 3 shows the onset of asthma-like syndrome in relation to the duration of exposure (less than one year or more than one year) and findings after stopping exposure.

\section{Discussion}

The duration of exposure during which asthma-like symptoms developed varied considerably. The interesting point is whether the difference in the duration of exposure could influence the prognosis of induced bronchial hyperreactivity after stopping exposure.

The view exists that inflammation is a pathological change in reactive airway dysfunction syndrome. ${ }^{6} \mathrm{~A}$ bronchial inflammatory reaction can be caused by inhalation of respiratory irritants, such as hydrogen fluoride, present in the working environment. As subepithelial irritant receptors are placed superficially they can be affected by an extensive bronchial inflammatory response, which might occur after heavy ${ }^{7}$ or continuous exposure to irritants. It seems that epithelial damage can also cause subtle disturbances of subcellular components such as tight junctions. Vagal sensory nerve endings are located beneath the tight junctions of the airway epithelium. Damage to the tight junctions could sensitise those receptors and result in an exaggerated reflex response. ${ }^{8}$ So, the time factor concerning the level and duration of exposure might be important. Despite the fact that no significant correlation was found between duration of exposure, and the speed of onset of respiratory symptoms and the later prognosis of the syndrome, such a possibility cannot be ruled out.

The lack of difference in the behaviour of workers with or without signs of atopy concerning their health state after stopping exposure confirms indirectly our views expressed earlier that the allergic type of mechanism is not responsible for the development of asthma in potroom workers.

On the other hand, the results obtained in the present study indicate that as a rule, once induced, bronchial hyperreactivity does not tend to disappear if exposure is discontinued. The improvement is mainly connected with lesser subjective complaints or even disappearance of respiratory symptoms. This accords with the findings of some other authors. ${ }^{5}$

In conclusion, based on the information collected reactive airway dysfunction syndrome, once induced, has a tendency to persist. Fewer subjective complaints may be expected, however, after stopping exposure. The reason for unchanged bronchial hyperreactivity in most of the workers, in spite of changed conditions as far as causal exposure is concerned, needs to be evaluated by further studies.

Table 3 Onset of asthma syndrome within first year of exposure and after longer exposure in relation to its persistence after stopping exposure

\begin{tabular}{|c|c|c|c|c|c|c|c|}
\hline \multirow[b]{3}{*}{ Duration of exposure } & \multicolumn{7}{|c|}{ Findings after stopping exposure } \\
\hline & \multicolumn{3}{|c|}{ Subjective symptoms (No of subjects) } & \multicolumn{4}{|c|}{ Bronchial hyperreactivity (No of subjects) ${ }^{\star}$} \\
\hline & $\begin{array}{l}\text { Without } \\
\text { changes }\end{array}$ & Improvement & Normalisation & $\begin{array}{l}\text { Without } \\
\text { changes }\end{array}$ & Improvement & Normalisation & Deterioration \\
\hline $\begin{array}{l}\text { (1) Less than one year } \\
\text { (2) More than one year }\end{array}$ & $\begin{array}{l}0 \\
4\end{array}$ & $\begin{array}{r}4 \\
14\end{array}$ & $\begin{array}{l}4 \\
4\end{array}$ & $\begin{array}{r}4 \\
16\end{array}$ & $\begin{array}{l}3 \\
1\end{array}$ & $\begin{array}{l}1 \\
3\end{array}$ & $\begin{array}{l}0 \\
2\end{array}$ \\
\hline
\end{tabular}

${ }_{\star}$ Difference between (1) and (2) is not statistically significant $\left(\chi^{2}=0.793 ; p>0.05\right)$. 
1 Sarić M, Gomzi M, Hrustić O, Pauković R, Rudan P. Respiratory impairment in the electrolytic extraction of aluminium. Int Arch Occup Environ Health 1979;42:217-21.

2 Saric $M$, Žuškin E, Gomzi M. Bronchoconstriction in potroom workers. Br J Ind Med 1979;36:211-15.

3 Sarić M, Godnić-Cvar J, Gomzi M, Stilinović L. The role of atopy in potroom workers asthma. Am J Ind Med 1986;9: $239-42$.

4 Wergeland E, Lund E, Waage JE. Respiratory dysfunction after potroom asthma. Am J Ind Med 1987;11:627-36.

5 O'Donnell TV, Welford B, Coleman ED. Potroom asthma: New Zealand experience and follow-up. Am J Ind Med 1989;15: 43-9.
6 Brooks SM, Weiss MA, Bernstein IL. Reactive airway dysfunction syndrome (RADS). Chest 1985;88:376-84.

7 Luo J-CJ, Nelsen KG, Fischbein A. Persistent reactive airway dysfunction syndrome after exposure to toluene diisocyanate. Br J Ind Med 1990;47:239-41.

8 Boushey HA, Holtzman MJ, Sheller JR, Nadel JA. Bronchial hyperreactivity: state of the art. Am Rev Respir Dis 1980;121:389-413.

Accepted 18 February 1991

From 1 July 1985 articles submitted for publication will not be returned. Authors whose papers are rejected will be advised of the decision and the manuscripts will be kept under security for three months to deal with any inquiries and then destroyed. 